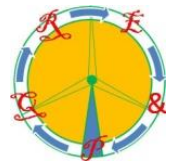

\title{
A review on the integration between urban and energy planning considering the planning tools
}

\author{
L. F. C. Castro ${ }^{1}$, B. B. Freitas ${ }^{1}$ and P. C. M. Carvalho ${ }^{1}$ \\ ${ }^{1}$ Department of Electrical Engineering \\ Federal University of Ceará \\ Campus Pici - Fortaleza, Ceará (Brazil) \\ Phone/Fax number: +0055 85999733738, e-mail: leonarda.cajuaz@pq.cnpq.br \\ e-mail: brenobf93@gmail.com, carvalho@dee.ufc.br
}

\begin{abstract}
The increasing energy demand is a global concern, directly associated with indicators of greenhouse gases and air pollution. These, in turn, are directly related to the physical, social and economic aspects of cities. One way to minimize such impacts is to diversify the energy matrix with renewable sources. On the other hand, the use of wind and solar plants are susceptible to multiple conflicts, due to urban aesthetics, technology scale or directionality of the energy flow across individual property limits. Considering that the urban form directly impacts the energy demand and the existence of conflicts arising from the use of renewable sources, the integration between urban and energy planning plays an important role in mitigating the risks associated with the growth of renewable generation. With such motivation, we propose a comparative analysis of the main tools of urban and / or energy planning through a systematic review of the literature. The methodology of the literature review and the results are presented through a table with the evaluated functionalities: Scenarios, simulations, energy conditioning, integration with GIS systems and ability to integrate with cities master plans.
\end{abstract}

Key words. Integrated Planning, Planning Tools, Urban Planning, Energy planning, Energy tools.

\section{Introduction}

Integration between energy and urban planning is of great importance considering that the need for energy, the control of greenhouse gases (GHG) and air pollution are directly related to the physical, social, economic and environmental aspects of cities [1]. Recent studies relate the urban form to the behaviour of energy demand, or even propose models of integration between urban and energy planning in order to reduce energy consumption and / or make it more efficient as well as reduce GHG emission. $[2 ; 3]$. Such studies are part of a sequence of researches that end up influencing or were influenced by the movement of researchers who highlight the importance of integrating planning in order to influence lifestyles through urban planning [4]. This line is reinforced by the 2030 agenda in the Sustainable Development Goal (SDG) 7, which has as one of its goals to substantially increase the share of renewable energy in the global energy matrix and expand infrastructure and modernize technology for the provision of modern and sustainable energy for all in developing countries, particularly in the least developed countries, according to their respective support programs [5]. With the incentives for distributed generation (DG) and its growth around the world, several studies have been developed in order to verify the impacts of DG in the technical and regulatory point of view [6,7,8]; others have evaluated the impact of urban morphology in generation, demand and / or energy efficiency $[9,10]$. The problems arising from the electricity generation using renewable sources can generate a series of aesthetic, environmental, social impacts, among others. The use of technologies such as wind and solar are susceptible to multiple conflicts, for example, due to the scale of the technology or the directionality of the energy flow across individual property limits [8]. On the other hand, more and more efforts are being made to optimize the efficiency of energy processes, from generation to final consumption. This has been registered through studies of energy communities, smart buildings and smart cities, albeit with an indirect approach. The complexity of rapid transition for these systems is related to the planning capacity integrating urban and energy issues, considering that each one has to occur in several aspects, which must be specific in a specific way. This can be attributed to: i) a difficulty in isolating the urban form and other urban parameters from the drivers of energy demand; ii) the fact that there are many variables in the cities to be considered and that the degree of interaction between each one is not yet fully defined and understood; iii) some urban attributes can have an antagonistic effect. For example, using a building's roof for PV generation excludes its use for solar water heating or green roofs. In addition, investing in skyscrapers to accommodate more 
people or increasing urban green areas with tall trees can also impact the solar irradiation that reaches the PV modules and, iv) there are not many empirically measured impacts in relation to the effects of adopting planning mechanisms at a city level. Master plans can be a tool for planning and controlling sustainable growth in cities, and are no longer a tool for controlling urban growth. The use of technological tools that are able to integrate the need for assessing urban growth integrated with energy demand taking into account risks such as aesthetic impact, as well as the right of access to the energy flow, is extremely important for the elaboration of a comprehensive and fundamental strategy in the application of development for sustainable cities in environmental, social and economic aspects. Considering the relevance of the theme, we propose a systematic review of the literature with the objectives: i) to identify the main proposals for the integration of urban and energy planning; ii) to highlight the main techniques, strategies and solutions on the theme, disregarding studies that deal with separate plans; iii) to highlight the main planning tools that approach the theme in an integrated manner in order to obtain the necessary basis to propose a solution taking into account the Brazilian scenario, due to the country's peculiar characteristics such as the increased use of DG using photovoltaic (PV) power [11]. The methodology used in the systematic review is presented and a comparative analysis of the main selected papers is carried out. The article is organized in: Section 2 presents the methodology, describing the sources used and the criteria for inclusion and exclusion of papers; Section 3 presents the main results through a separation according to the main theme identified; Section 4 presents a critical analysis of research opportunities resulting from identified limitations and gaps; Section 5 discusses related papers, and concluding remarks are presented in Section 6.

\section{Review Methodology}

This section describes the methodology used for a literature review related to the integration between urban and energy planning. The review is conducted following the procedure described in [12], with the following specific questions: "What are the existing tools and criteria applied for integrated planning?" and "What are the principles and criteria for assessing the Integration of Urban and Energy planning?". The specific review protocol is defined using a specific tool for systematic reviews, in order to include the maximum possible number of studies in the area. The electronic databases used are: Science Direct, Scopus, and Medeley. Initial searches produced 2311 matches. After the first list of articles, an initial classification was performed considering the exclusion of the duplicated articles and reclassification regarding the exclusion criteria by correlation with the topic under study. The Flowchart shown in Fig. 1 represents the phases taken in our systematic review. After the third phase of analysis, the articles were classified as follows: 1922 excluded, 3 duplicated, 12 unclassified and 374 accepted papers. This result is found in Fig. 2. The exclusion criteria are: Study related to the use of BIPV, situation of the use of DG, simply representing a literature review, that is, without proposing a new contribution, dealing with specifically related regulatory acts the generation of electric energy; and present case studies not applicable to the Brazilian scenario, Aesthetic impact of solar energy systems, $\mathrm{CO} 2$ emissions and urban and energy resilience. The analysed articles were published between 2012 and 2021 and are considered in journals indexed in international systems in the English language and available in full for reading. This stage was called the quantitative phase of the research.
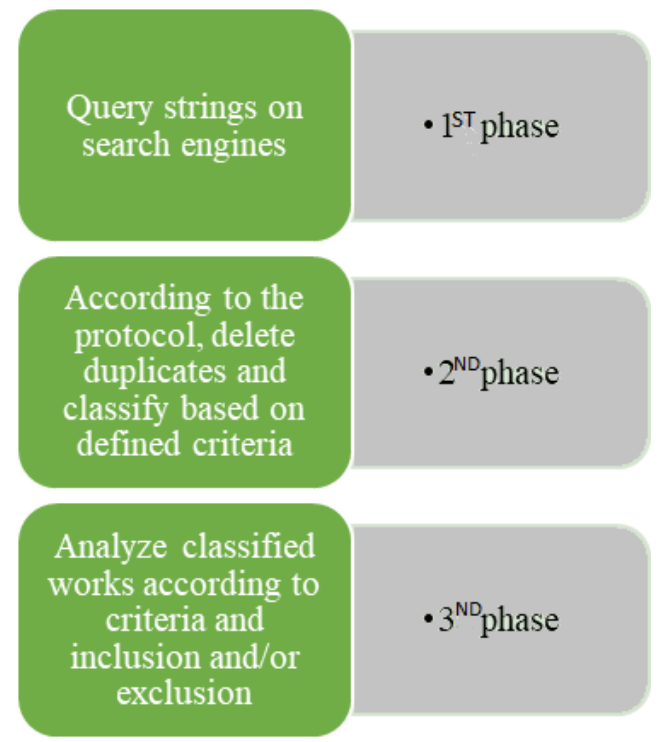

Fig 1. Flowchart of the Systematic Review process

\section{Status}

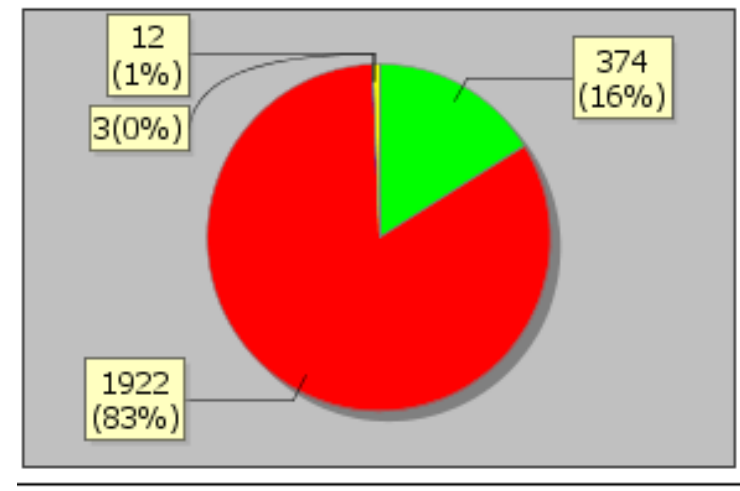

- Accepted $\bullet$ Rejected $\bullet$ Duplicated $\bigcirc$ Unclassified

Fig. 2 Initial number of papers collected and classified according to exclusion, inclusion and duplication criteria

The qualitative step was carried out from the analysis of the abstracts considering the level of detail and approach on the topics of inclusion in the research, reclassifying the articles for reading priority that ended with a total of 120 articles. Each of these articles has its relevant attributes with author, title, year of publication, place of publication and DOI organized in a database to facilitate access to this information. The result of this classification is shown in Fig. 3.

The 120 articles classified with very high priority were read in full and of these 34 were selected due to the relationship of congruence with the topic under study and importance to answer the questions proposed in our paper. 
Reading Priority

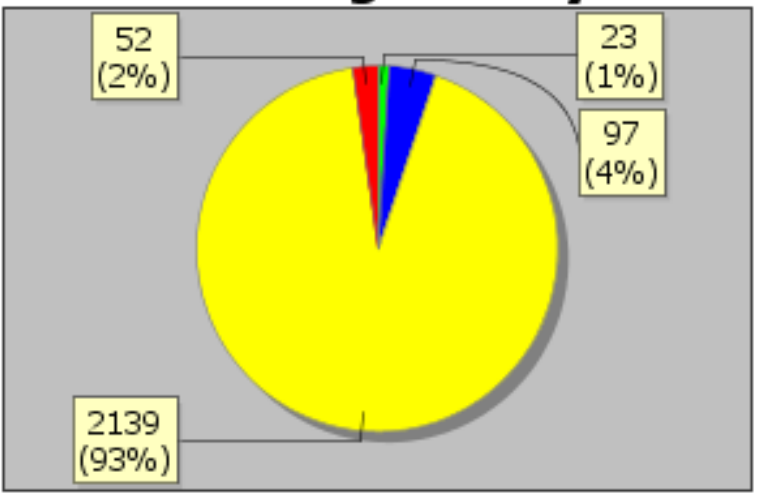

Very High $\bullet$ High $\bigcirc$ Low $\bullet$ Very Low

Fig. 3. Qualitative step result of classification O TEXTO FALA DE 120 ARTIGOS!

\section{Review Results}

After the evaluation of selected articles that deal with integration tools between urban and energy planning, 20 programs with characteristics within the research scope are identified: Balmorel [13], CEA (City Energy Analyst) [14], Dieter (Dispatch and Investment Evaluation Tool with Endogenous Renewables) [15], District ECA [16], EnergyPlan [17], EnergyPro [18], Grid LAB-D [19], Homer PRO [20], HUES [21], iHOGA (Improved Hybrid Optimisation by Genetic Algorithm) [22], Insel (Integrated Simulation Environment Language) [23], Oemof (Open Energy Modelling Framework) [24], OSeMOSYS (Open
Source Energy Modeling System) [25], RETScreen [26], SIREN (SEN Integrated Renewable Energy Network) [27], Solarius PV [28], SOLergo [29], Synergi Electric [30], Urbs [31] e WebOpt (Distributed Energy Resources Web Optimisation Service) [32]. For each paper and according to the literature, five functionalities are analyzed:

1) Simulation, i. e., whether the tool has the ability to simulate the electricity production from an energy system and obtain the plant compensation level.

2) Scenario generation capacity, where generation forecasts with defined intervals can be prepared.

3) Energy conditioning, in which the process of adequacy of the energy supply and the grid absorption are analysed.

4) Tool integration with Geographic Information System (GIS), providing accurate evaluation of the site geographical conditions making the system more suitable for local characteristics.

5) Capacity of integration with cities master plans, in which the implementation of the power generation system considers data such as exclusion of environmental preservation areas, vertical growth of each region and land occupation.

The tools are gathered and summarized in Table 1 according to the mentioned functionalities.

Table 1 - Classification of tools

\begin{tabular}{|c|c|c|c|c|c|}
\hline \multirow{2}{*}{$\begin{array}{c}\text { Evaluated } \\
\text { Tools }\end{array}$} & \multicolumn{5}{|c|}{ Functionalities } \\
\hline & Simulation & Scenario & Energy Conditioning & GIS & $\begin{array}{l}\text { Integration with } \\
\text { Master Plan }\end{array}$ \\
\hline Balmorel & Yes & Yes & Yes & No & No \\
\hline CEA & Yes & Yes & Yes & Yes & Yes \\
\hline Dieter & Yes & Yes & Yes & No & No \\
\hline District ECA & Yes & Yes & Yes & Yes & No \\
\hline EnergyPlan & Yes & Yes & Yes & Yes & No \\
\hline EnergyPro & Yes & Yes & Yes & No & No \\
\hline Grid LAB-D & Yes & Yes & Yes & Yes & Yes \\
\hline Homer PRO & Yes & Yes & Yes & Yes & Yes \\
\hline HUES & Yes & Yes & Yes & Yes & No \\
\hline iHOGA & Yes & Yes & Yes & No & No \\
\hline Insel & Yes & No & Yes & No & No \\
\hline Oemof & Yes & No & Yes & Yes & No \\
\hline OSeMOSYS & Yes & Yes & Yes & Yes & No \\
\hline RETScreen & Yes & Yes & Yes & No & No \\
\hline SIREN & Yes & Yes & Yes & Yes & Australia Only \\
\hline Solarius PV & Yes & Yes & No & Yes & Yes \\
\hline SOLergo & Yes & Yes & No & Yes & No \\
\hline Synergi Electric & Yes & Yes & Yes & Yes & No \\
\hline Urbs & Yes & Yes & Yes & No & No \\
\hline WebOpt & Yes & Yes & Yes & No & USA Onlyx \\
\hline
\end{tabular}

Fig. 04 shows the number of functionalities of each tool. This becomes a selection factor for choosing tools that deal with the integration between energy and urban planning, since the two biggest differentials are GIS, which provides local climatic and related conditions, and
Integration with Master Plans, which subdivides and classifies the city between socially and environmentally appropriate regions and the unviable regions. 


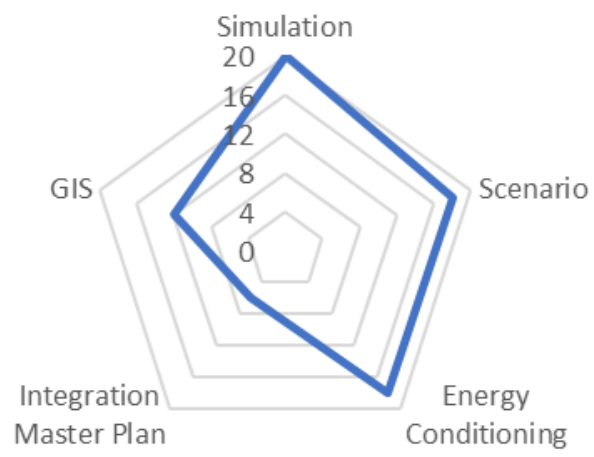

Série 1

Fig.4. Number of functionalities of the tools

Among the analyzed methodologies, the Urban Planning Sustainability Framework UPSUF is based on a Geographic Information System (GIS) which allows an evaluation of the urban space in its current condition. This methodology works in five stages as shown in Figure 5. The first stage is basic conditions for local development, or the pre-development scenario; in the second, the survey of information that depends on the type of redevelopment that is desired, and depending on this we can involve data on the ecology of the place, current infrastructure, land use and hydrology. Based on these data and using the GIS tool, an evaluation of the existing urban form is made considering the dimensions, shape, orientation and spacing of the construction, as well as the characteristics of the artificial surfaces and the amount of green spaces and the availability of natural resources in the area under analysis. Such data will be processed in relation to the baseline and a new urban development is proposed at this third stage. For the conclusion of the process, the fourth stage is carried out with a standard of evaluation of the new Urban Development based on the guidelines of urban planning, in order to verify if the proposal is considered sustainable. UPSUF allows you to integrate a number of tools, including NCPT (Natural Capital Planning Tool) or B£ST (Benefit Estimating Tool), among others. In addition to allowing during the case study processes, certification processes such as BREEAM (Building Environmental Assessment Method for Research Establishment; BRE Global, 2017), LEEDND (Leadership in Energy and Environment Project) can also be inserted. This ability is extremely important when evaluating the result resulting from the visual representation of urban development using a GIS tool, since it can combine the results of the visual representation with the sustainability indicators defined within the certification and certification processes. Closing of the process takes place in the fifth stage after the application of the structure involves a comparison of the results with the reliable sustainability metrics [33].

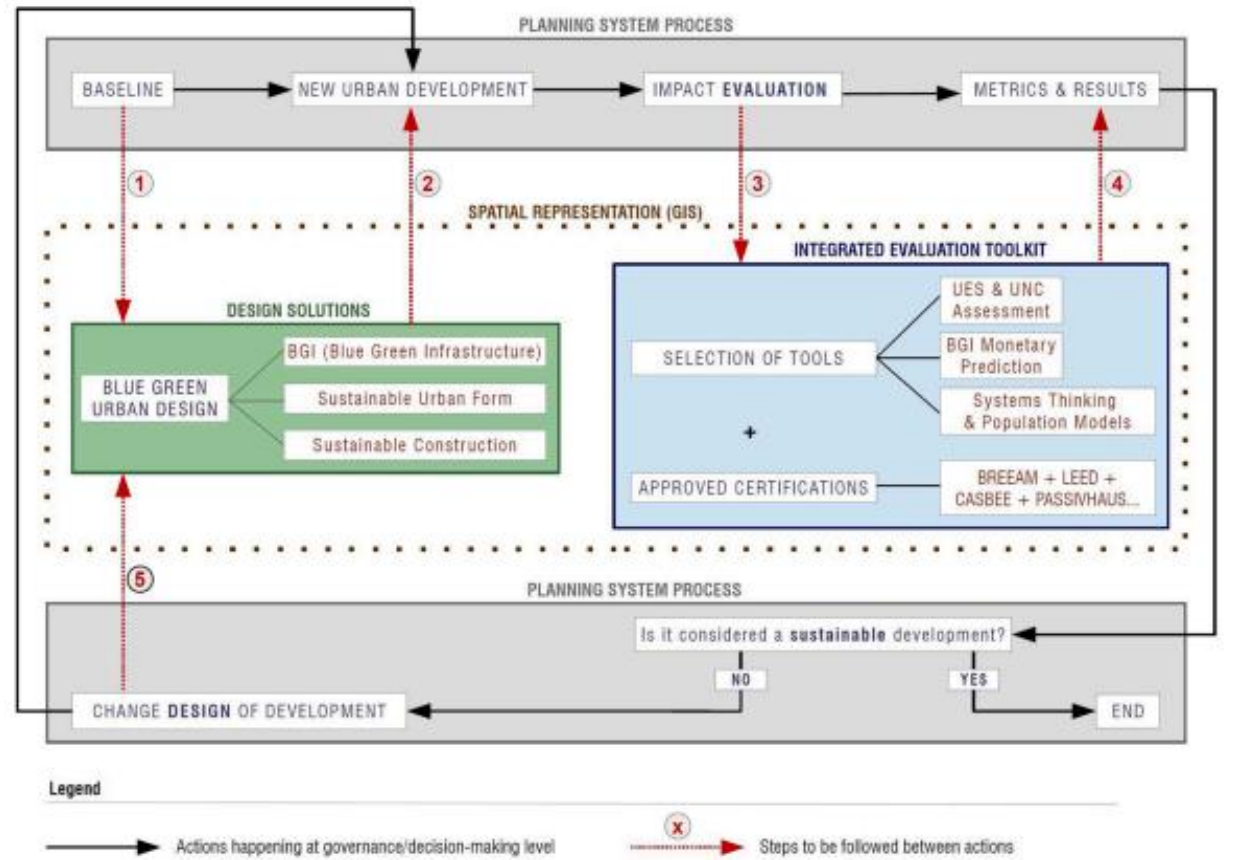

Fig.5. UPFSC stages

The second model analysed is the one developed in the work [2] that makes use of The Long-range Energy Alternatives Planning System (LEAP) energy simulation model was applied for modelling Sao Paulo's Urban Energy Systems (UES) in order to characterize the megacity current and future energy system. In this work, the energy and urban planning strategies applied to the entire urban system (all sectors and not just buildings or transport) were modeled, relating the urban use of energy, identifying connections and each of the respective parameters with the corresponding municipal services. These services that the city must provide include housing, mobility, job offers, education, health, food and water supply, leisure and security. In turn, the provision of these city services is affected by: (i) the city's infrastructure (built environment, city density, 
transport infrastructure and other infrastructure to support the supply of energy, waste, water and collection and sewage treatment) and (ii) city resources available, or city resources (ie water, food, energy and waste goods that can be imported or produced locally). The paper presents an integrated solution matrix of energy and urban planning strategies. This holistic and multisector approach for Urban and Energy Planning (UEP) integrated synergies assessment was made by evaluating: (i) urban energy savings (ie focusing not only on energy efficiency, but also on energy conservation), (ii) GHG emission reductions, and (iii) local and RES electricity production opportunities / possibilities. The matrix was applied to the Sao Paulo megacity (Brazil). A total of 29 Urban Planning (UP) and Energy Planning (EP) strategies and solutions were selected and simulated using the LEAP_SP model to envision Sao Paulo's future energy system (2014 and 2030) and to quantify possible synergies. These strategies were simulated over four scenarios, as follows: Historical Rates (SHR), Energy Policies strategies (SEP), Urban Policies strategies (SUP) and Urban and Energy Policies strategies (SUEP). Figure 6 presents the integrated energy matrix and the urban planning strategies proposed by the study, which can be applied to both existing and new cities.

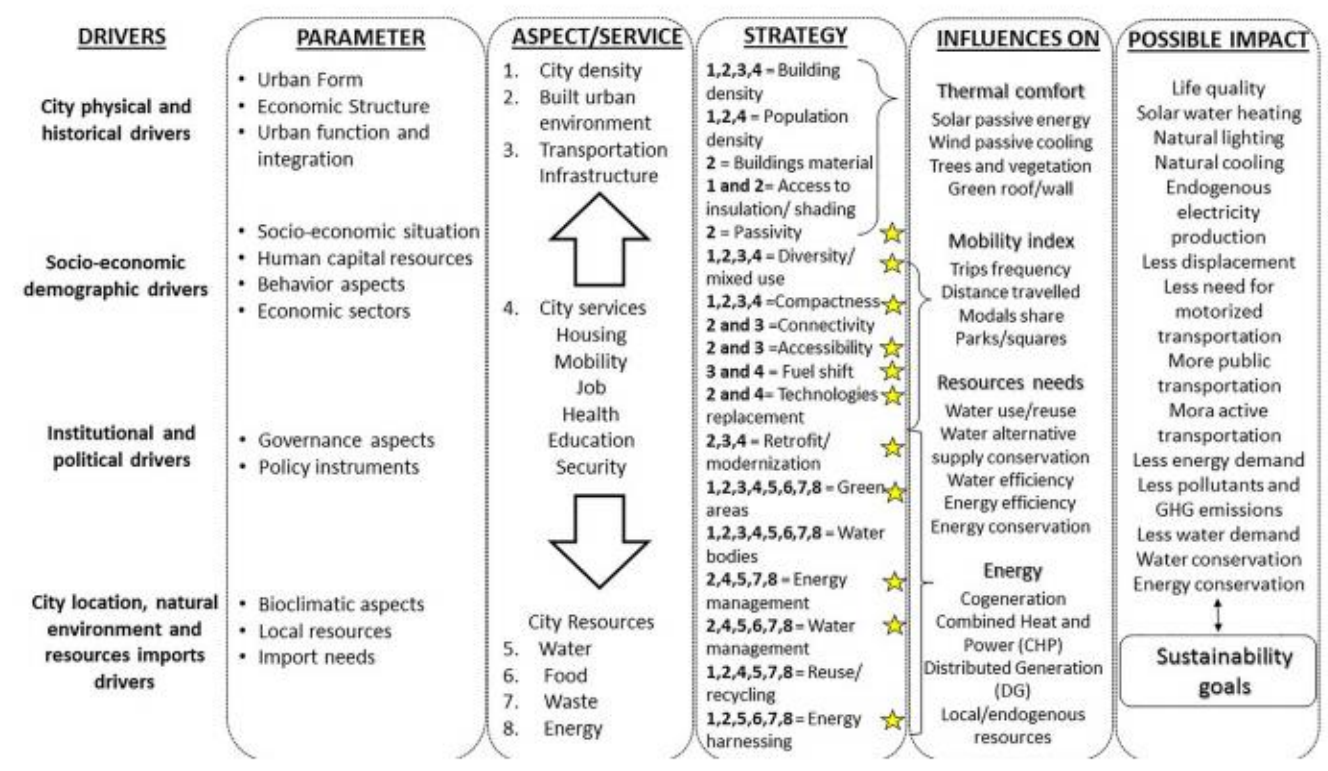

Fig.6. Integrated solutions matrix of energy and urban planning.

From the definition of the drivers to be used as well as the parameters corresponding to each drive, aspects and / or services correlated directly or indirectly to each parameter are defined. From here, urban and energy planning strategies are defined considering the interdependence relationship between the defined aspects / services and thus defined the relationship of influence of these strategies. As a result, we have the possible impacts expected from the implementation of established strategies.

\section{Conclusion}

In our article we focus on the planning tools considering the following characteristics: ability to simulate the electrical energy production, obtaining compensation for the level of installation; ability to generate scenarios, where generating output can be obtained at defined intervals; energy conditioning, in which courses are taken to adapt the necessary and absorb energy from the grid; integration with GIS, providing accurate assessment of geographical conditions making the system more suitable to local characteristics and subject to integration with city master plans, in which the implementation of the power generation system considers data such as exclusion of environmental preservation areas, vertical growth of each region and land occupation. With regard to the methodologies, those that are applied specifically to renewable energies and / or distributed generation in urban areas were disregarded from the studies since the objective is to identify the best methodologies for the integration of urban and energy fullness in a general. The results come from a systematic review of the literature that seeks to analyze the main contributions related to the tools and methodologies of Urban and Energy Planning in an integrated manner. The adopted methodology is applied and a summary of the selected tools is presented as a way to facilitate access to information. Currently, of the 20 existing and evaluated tools, only 5 meet all functionalities; 2 of them, SIREN and WebOpt, are specifically applicable to their countries. A critical consideration is the lack of integration with GIS systems, since this technology allows the real-time update of the urban form. Among the papers related to the methodology, only 2 were selected: UPSUF, the study with LEAP_SP considering that both allow integration with other tools, has the ability to bring information about the current and desirable state of urban and energy planning; both with tested applications for specific situations, the first being applied to the area of service and water management in England and the second to the strategic energy planning of the metropolis of São Paulo Brazil. The difference found and considered as relevant in this study is the fact that the UPSUF methodology 
allows integration with tools for accreditation of sustainable processes, thus allowing the evaluations carried out to take into account the indicators defined in these processes. The importance of this benefit is highlighted by the fact that the planning process is somewhat continuous and, consequently, the Japanese tool can direct corrective and / or improvement actions on a continuous basis, besides that it already guarantees a certification of the process can add value with credit of carbon, measurement and verification of energy efficiency processes, among others. As future work, we suggest the feasibility of integration between one of the five selected tools, the UPSUF method in order to assess the degree of complexity of real application considering the matrix proposed by LEAP_SP as a service differential for several segments and not only for a specific application.

\section{Acknowledgement}

FUNCAP for master's scholarship awarded to the second author and $\mathrm{CNPq}$ for researcher scholarship awarded to the third author.

\section{References}

[1] Cajot, S., et.al. Obstacles in energy planning at the urban scale, Sustainable Cities and Society (2017). Vol. 30, pp 223-36. https://doi.org/10.1016/j.scs.2017.02.003

[2] Collaço, F.M.A., et.al. The dawn of urban energy planning e Synergies between energy and urban planning for São Paulo (Brazil) megacity; Journal of Cleaner Production (2019). Vol. 215, pp 458-79. https://doi.org/10.1016/j.jclepro.2019.01.013

[3] Creutzig, F., et.al. Urban infrastructure choices structure climate solutions. Nat. Clim. Change (2016). Vol. 6, pp 1054-56. https://doi. org/10.1038/nclimate3169.

[4] Yazdanie, M., Densing, M. and Wokaun, A. Cost optimal urban energy systems planning in the context of national energy policies: a case study for the city of Basel. Energy Policy (2017). Vol. 110, pp 176-90. https://doi.org/10.1016/j.enpol. 2017.08.009.

[5] Objetivo de Desenvolvimento Sustentável 7. Disponível em:https://nacoesunidas.org/pos2015/ods7/. Acessed in: 26/11/2020.

[6] Fidalgo, J.N. and Fontes, D.B.M.M. Fostering microgeneration in power systems: The effect of legislative limitations, Electric Power Systems Research (2012). Vol. 84, pp 181-86. https://doi.org/10.1016/j.epsr.2011.11.013

[7] Adil, A.M. and Ko, Y. Socio-technical evolution of Decentralized Energy Systems: A critical review and implications for urban planning and policy, Renewable and Sustainable Energy Reviews (2016). Vol. 57, pp 1025-37. https://doi.org/10.1016/j.rser.2015.12.079

[8] Silva, S., Oliveira V. and Leal, V. Urban Form and Energy Demand: A Review of Energy-relevant Urban Attributes, Journal of Planning Literature (2017). Vol. 32(4) 346-65. https://doi.org/10.1177\%2F0885412217706900

[9] Zhu, R., et.al, The effect of urban morphology on the solar capacity of three dimensional cities", Renewable Energy (2020). Vol. 153, pp 1111-26. https://doi.org/10.1016/j.renene.2020.02.050

[10] Vermeylen, S. Resource rights and the evolution of renewable energy technologies, Renewable Energy (2010). Vol. 35, pp 2399-405. https://doi.org/10.1016/j.renene.2010.03.017
[11] Associação Brasileira de Energia Solar Fotovoltaica. Infográfico http://www.absolar.org.br/infografico-absolar.html. Acessado em: $\langle 16 / 02 / 2021>$

[12] Pullin, A.S., Stewart, G.B. Guidelines for systematic review in conservation and environmental management. Conservation Biology (2006). Vol. 20, Issue 6, pp 164756. https://doi.org/10.1111/j.1523-1739.2006.00485.x

[13] Balmorel. <http://www.balmorel.com/> [Accessed 09.01.21]

[14] Fonseca J A, Nguyen T, Schlueter A and Marechal F. City Energy Analyst (CEA): integrated framework for analysis and optimization of building energy systems in neighborhoods and city districts. Energy and Buildings (2016). Vol. 113, pp 202-26. https://doi.org/10.1016/j.enbuild.2015.11.055

[15] Dieter. DIW Berlin. <http://www.energy-workshop.cz/pdfwednesday/zerrahn.pdf $>$ [Accessed 23.07.20]

[16] District ECA. Fraunhofer Institute for Building Physics IBP. <https://www.district-eca.de/index.php?> [Accessed 23.01.21]

[17] EnergyPLAN. Sustainable Energy Planning Research Group. <https://www.energyplan.eu/> [Accessed 22.01.21]

[18] EnergyPRO. EMD International. <https://www.emd.dk/energypro/> [Accessed 21.01.21]

[19] GridLAB-D. U.S. Department of Energy (DOE). <https://www.gridlabd.org/> [Accessed 22.01.21]

[20] Lambert T, Gilman P and Lilienthal P. Micropower system modeling with HOMER. Integration of alternative sources of energy. 2006:379-418.

[21] HUES. <https://hues-platform.github.io/> [Accessed 21.01.21]

[22] IHoga. <https://ihoga.unizar.es/> [Accessed 22.01.21]

[23] Bernal-Agustín JL, Dufo-Lopez R. Efficient design of hybrid renewable energy systems using evolutionary algorithms. Energy Convers Manag (2009). Vol. ;50, pp 479-89. https://doi.org/10.1016/j.enconman.2008.11.007

[24] Oemof. <https://oemof.org/> [Accessed 21.01.21]

[25] Howells M. and et.al. OSeMOSYS: the open source energy modeling system: an introduction to its ethos, structure and development. Energy Policy (2011). Vol. 39, pp 5850-70. https://doi.org/10.1016/j.enpol.2011.06.033

[26] RETScreen. Natural Resources Canada. $<$ https://www.nrcan.gc.ca/maps-toolspublications/tools/data-analysis-softwaremodelling/retscreen/7465> [Accessed 23.01.21]

[27] SIREN. SEN. $\langle$ https://www.sen.asn.au/modelling_overview> [Accessed 23.01.21]

[28] SOLergo. Electro Graphics. <https://www.electrographics.com.br/produtos/solergo> [Accessed 20.01.21]

[29] Solarius PV. ACCA Software. $<$ https://www.accasoftware.com/ptb/softwarefotovoltaico $>$ [Accessed 19.01.21]

[30] Synergi Electric <https://www.dnvgl.com/services/powerdistribution-system-and-electrical-simulation-softwaresynergi-electric-5005> [Accessed 23.01.21]

[31] Urbs. Universidade Técnica de Munique. <https://urbs.readthedocs.io/en/latest/index.html> [Accessed 23.01.21]

[32] Web Optimization Service (WebOpt). DER-CAM. $<$ https://china.lbl.gov/der-cam> [Accessed 21.01.21]

[33] Puchol-Salort, P., Mijic, A., Reeuwijk, M.V. and O'Keeffee, J. An urban planning sustainability framework: Systems approach to blue green urban design http://dx.doi.org/10.13140/RG.2.2.35973.78563 